\title{
Errata
}

\section{Erratum: Thermal Expansion of Platinum and Platinum-Rhodium Alloys}

\author{
R. E. Edsinger, M. L. Reilly, and J. F. Schooley \\ National Institute of Standards and Technology, \\ Gaithersburg, MD, 20899
}

J. Res. Natl. Inst. Stand. Technol., Volume 91, Number 6, November-December 1986, p. 333 http://dx.doi.org/10.6028/jres.091.037

Erratum: Equation (22) contains an error. It should read

$$
100 \varepsilon\left(t, 0^{\circ} \mathrm{C}\right)=8.79 \times 10^{-4} t+0.805 \times 10^{-7} t^{2} .
$$

Also, the data presented in Table 12 under the column Day and Sosman Eq. (22) should be evaluated by using the corrected Eq. (22) above.

Acknowledgement: The authors thank G. K. Schwenke, metallurgist at Corning Incorporated, for bringing the error to our attention. 